The Clock Is Ticking! Executive Temporal Depth, Industry Velocity, and Competitive Aggressiveness

\author{
Sucheta Nadkarni \\ Judge Business School \\ University of Cambridge \\ Phone: +44 1223339700 \\ Email: s.nadkarni@jbs.cam.ac.edu
}

\author{
Tianxu Chen \\ Oakland University \\ Phone: (248) 370-3290 \\ Email: tchen234@oakland.edu
}

Jianhong Chen

University of New Hampshire

Phone: (215) 200-7479

Email: jianhong.chen@unh.edu

Acknowledgements: We gratefully acknowledge insightful suggestions of Dr. Margarethe F. Wiersema (associate editor) and two anonymous reviewers. We also received helpful suggestions on earlier versions of the manuscript from Ming-Jer Chen, Tieying Yu and scholars at the Chinese Management Scholar Workshop, Boston, 2012. 


\title{
The Clock Is Ticking! Executive Temporal Depth, Industry Velocity, and Competitive Aggressiveness
}

\begin{abstract}
Research summary: we examine how the interplay between executive temporal depth (time horizons that executives consider when contemplating past and future events) and industry velocity (the rate at which new opportunities emerge and disappear in an industry) shapes competitive aggressiveness (a firm's propensity to challenge rivals directly and intensely in order to maintain or improve its market position) and firm performance. Based on panel data (from 1995 to 2000) from 258 firms in 23 industries, we found that executive temporal depth exhibited different patterns of relationships with competitive aggressiveness in low- and high-velocity industries. Moreover, competitive aggressiveness had a positive main effect on firm performance but this effect was stronger in high-velocity industries than in low-velocity industries.

Managerial summary: This article informs that the executive past and future time horizons needed to enhance competitive aggressiveness and performance in fast changing and slow changing industries are different. Our results show that in fast changing industries, executives with short-term thinking about the past and moderate-term thinking about the future maximize competitive aggressiveness and performance of their firms. In contrast, in slow changing environments, executives with long-term past and long-term future thinking achieve superior competitive aggressiveness and firm performance.
\end{abstract}

Keywords: Competitive dynamics, temporal orientation, executive cognition, and competitive aggressiveness 
Based on the Austrian view of the market as a disequilibrium system (Kirzner, 1997), competitive dynamics research rests on the premise that changing conditions render a firm's positioning in a competitive market temporary either in the short run or the long run (Chen and Miller, 1994; D’Aveni, Dagnino and Smith, 2010; Ferrier, 2001; Ferrier, Smith, and Grimm, 1999). This inherently temporal nature of competitive phenomena has brought the issue of time to the forefront of research on competitive dynamics. This research has identified two sets of temporal forces governing the creation and erosion of competitive advantage - macro and micro. Industry-level macro temporal forces (e.g., hypercompetition, dynamism and velocity) define the time windows of opportunities available for incumbents to establish new advantages and negate the advantages of competitors and impose different levels of pressure on incumbents to retaliate (Chen et al., 2010b; D’Aveni et al., 2010; Davis, Eisenhardt and Bingham, 2009; Katila, Chen, and Piezunka, 2012; Rindova, Ferrier, and Wiltbank, 2010). Micro temporal forces, in the form of speed, intensity, timing and sequences of actions taken by individual firms, determine their competitive advantages over rivals and in turn their survival and success (Derfus et al., 2008; Ferrier, 2001). Firms that take speedy and frequent competitive actions are better positioned competitively and show superior performance (Katila and Chen, 2008; Rindova et al., 2010).

Despite the rich insights yielded by this literature, several gaps remain in our understanding of how time manifests in competitive dynamics. A particularly prominent gap pertains to the limited understanding of how executives' temporal orientations (relatively stable tendencies in evaluating and interpreting time) shape competitive behaviors. This gap is especially important because competitive dynamics scholars recognize that "competitive actions can be seen as products of the perceptions... of (competitive) actors in an organization" (Chen and Miller, 2012: 29). Building on the upper echelons perspective (Hambrick and Mason, 1984), this research emphasizes that executive orientations create filters in how they notice and interpret competitive cues and in turn determine a firm's overall propensity to initiate new and responsive actions (Chen and Miller, 2012). Studies have shown that cognitive categorization of competitors (Porac, Thomas and Baden-Fuller, 1989; Reger and Huff, 1993), competitor acumen (Tsai, Su and Chen, 2011), cognitive frameworks 
(Marcel, Barr and Duhaime, 2011) and perceived competitive tension (Chen, Su, and Tsai, 2007) explain additional variance beyond that caused by industry and firm factors.

Research on the subjective perspective of time in strategy has also stressed that executives' temporal orientations mold expectations and evaluations of decision situations and form the basis of executives' strategic choices (Ancona et al., 2001; Bluedorn, 2002; Das, 1987). Studies have shown that temporal heuristics and preferences used by managers in sequencing and pacing activities are critical to capturing new opportunities, becoming informed of external environmental changes and adjusting firm strategies to these changes (Bingham and Eisenhardt, 2011; Gersick, 1994). This research suggests that executives' temporal orientation likely serves as a third temporal force in determining competitive behaviors of firms.

We address this gap by examining the role of executive temporal orientation in driving competitive behaviors of firms. We capture executive temporal orientation by the concept of temporal depth, which refers to the temporal distance into the past and the future that executives typically consider when contemplating events that have happened or may happen (Bluedorn, 2002; Bluedorn and Martin, 2008). Time horizons are fundamental aspects of a firm's strategic orientation (Das, 1987). Short time horizons provide flexibility and quick adaptation but also give rise to temporal myopia and economic short-termism (Laverty, 1996; Marginson and McCaulay, 2008). Long time horizons lend foresight in management but delay short-term adaptation to changing environmental conditions (Levinthal and March, 1993; Miller, 2002). Therefore, variation in consideration of time horizons has implications for strategic choices (Laverty, 1996; Marginson and McAulay, 2008; Souder and Bromiley, 2012).

Anecdotal examples show that executives vary in their temporal depth orientation, which guides their strategic philosophy. A Financial times article in 2009 described Jack Welsh, CEO of GE, as the "father of the (short-term) shareholder value movement." Dowd and Hutchinson (2010: 150) explain how "Jack Welsh used short-term results to determine bottom ranking 10 percent of managers each year so he could fire them." In contrast, the following quotes from Costco CEO James Sinegal's interviews illustrate his long-term orientation: 
"I think the biggest single thing that causes difficulty in the business world is the short-term view. We become obsessed with it. But it forces bad decisions" - (Ethix, 2003)

"Wall Street is in the business of making money between now and next Tuesday. We're in the business of building an organization, an institution that we hope will be here 50 years from now." - (The Motley Fool, 2013)

This long temporal depth has defined Costco's strategic philosophy of treating employees as a future investment (e.g., paying higher wages and benefits and opportunities for growth) and focusing on long-term customer loyalty (e.g., membership programs) rather than short-term sales.

We propose that the relationship between executive temporal depth, competitive behaviors and firm performance will be moderated by industry velocity, defined as the rate at which new opportunities emerge and disappear in an industry (Davis et al., 2009; Eisenhardt and Martin, 2000). By determining how quickly technologies, products and competitive actions become obsolete in an industry, industry velocity sets the competitive clock for incumbent firms to act and react. Therefore, we contend that a match between executive temporal depth and the wavelength implied by industry velocity (short vs long duration of competitive change cycles) will enhance competitive behaviors and in turn firm performance, whereas a mismatch between the two will undermine both. We conceptualize competitive behaviors as competitive aggressiveness, a fundamental concept capturing inter-firm rivalry (Chen et al., 2010a). It is defined as "the propensity of a firm to directly and intensely challenge rivals in order to maintain or improve its market position" (Yu, Subramaniam, and Cannella, 2009: 128). We test this model using panel data (1995 - 2000) on 258 firms from 23 industries.

This study advances existing research in two ways. First, it extends research on time in competitive dynamics by introducing a third temporal force-executives' temporal orientation. This subjective perspective of time complements research on both industry-level (macro) temporal forces and firm-level (micro) competitive behaviors. By integrating research on the three temporal forces, this study presents a more complete understanding of how time manifests in competitive dynamics. Second, whereas strategy research has focused almost exclusively on future time horizons, we examine the impact of both past and future time horizons on competitive behaviors and firm 
performance. By highlighting the distinct relationships of executive past and future time horizons to competitive aggressiveness in varied industry velocity contexts, this study presents a more finegrained conceptualization of time horizons in strategy.

\section{THEORY DEVELOPMENT}

\section{Research on time in competitive dynamics}

Competitive dynamics research has identified two temporal forces-macro and micro. Macro temporal forces are temporal features of the environment that serve as time givers and determine the degree to which the competitive advantage enjoyed by incumbent firms is temporary or sustainable (Miller and Chen, 1996; Derfus et al., 2008). Several temporal features of the environment have been identified, including hypercompetition (Chen et al., 2010a; D’Aveni et al., 2010; Thomas and D’Aveni, 2009), industry velocity (Eisenhardt and Martin, 2000), industry dynamism (Davis et al., 2009), market uncertainty (Chen and Miller, 1994) and nascent versus established industries (Chen et al., 2010b; Katila et al., 2012; Rindova et al., 2010). Micro temporal forces are reflected in the actions taken by individual firms in creating and pursuing new opportunities. Temporal features of firm actions, such as speed, timing, volume and unpredictability, have been shown to influence firm performance (Ferrier, 2001; Katila and Chen, 2008; Rindova et al., 2010).

A key notion of this research is that macro (industry-level) and micro (firm-level) temporal forces interact in shaping inter-firm rivalry. Because the competitive rules of success and the temporal contingencies facing incumbent firms are unique to an industry, performance benefits that firms derive from action attributes such as speed and volume depend on the temporal features of the industry (Chen and Miller, 1994; Derfus et al., 2008; Ferrier, 2001). Chen et al. (2010b) and Katila et al. (2012) found that the frequency and type (exploratory and exploitative) of R\&D and market moves yielded different levels of firm performance in new and established markets. Similarly, Chen et al. (2010a) found that action speed and volume were more strongly associated with superior performance in fast-changing, hypercompetitive industries than in slow-changing industries. Finally, Rindova et al. (2010) found that simple and predictable sequences of competitive moves received higher investor evaluation in nascent industries. 
Together, this research highlights that both firm and industry temporal forces are central to determining competitive behaviors and outcomes. We add to this existing body of literature by theorizing that subjective perspective of time is likely to serve as a third temporal force in shaping the creation and erosion of competitive advantage.

\section{Subjective perspective of time in competitive dynamics}

Drawing on the upper echelons theory (Hambrick and Mason, 1984), competitive dynamics studies have stressed the subjective basis of competitive behaviors. As top managers sift through and reconcile large amounts of incomplete, ambiguous and conflicting data, their orientations and perceptions enter greatly into the decision to undertake a competitive action (Chen and Miller, 2012; Hambrick, Cho and Chen, 1996). This literature has identified executive awareness as a key driver of problem sensing, interpretation and enactment of environmental cues, and in turn of competitive behaviors (Marcel et al., 2011). Perceptual filters enhance or inhibit executives' awareness of the relevant cues in the competitive environment and determine the degree to which executives can accurately gauge critical threats and opportunities and match perceived problems with strategic solutions (Chen, 1996; Ferrier, 2001). As Chen et al. (2007: 103-104) state "Indeed, the perceptions of decision makers ...- - the level of competitive apprehension or anticipation they feel as they observe, filter, and act on competitive information - inform the way a firm acts (strategically or competitively) on those perceptions." Porac and Thomas (1990: 228) also explain how “decision makers make sense of competitive environments by developing cognitive taxonomies that summarize the similarities and differences among (rival) organizations." Similarly, Livengood and Reger (2010) emphasized that how the firm sees itself and its domain in the competitive arena can help explain why firms act and react the way they do. Strategists' inaccurate assumptions about the competitive landscape create blind spots or judgmental impairment, prompting them to overlook the emergence of a new rival (Chen \& Miller, 2012).

Empirical evidence supports the subjective nature of inter-firm rivalry. Porac et al. (1989) found that Scottish knitwear manufacturers varied in their definition of competitors and criteria for competing. Reger and Huff (1993) showed that incumbent firms clustered competitors based on 
their perceptions of shared strategic commonalities among rivals. Recent studies have found that executives' competitor acumen (Tsai et al., 2011), perceived competitive tension (Chen et al., 2007) and cognitive frameworks (Marcel et al., 2011) drive competitive behaviors and outcomes.

However, this literature has not addressed executives' temporal orientation. This gap is especially important because strategy scholars increasingly emphasize that strategic decisions are made by individual strategy makers whose temporal orientation cannot be ignored because such omitting provides "a misleading conception of time when it relates to strategy making" (Das, 2004: 59). According to this view, executives mentally create their own "temporal zones" (e.g., short-term versus long-term) when deciding on strategic actions, irrespective of the actual environment they face (Barringer and Bluedorn, 1999; Huy, 2001). These temporal orientations serve as temporal filters that mold expectations and evaluations of decision situations and form the basis of choices related to resource allocation and prioritization, as well as recognition of the timing and urgency of strategic activities (Das, 1987). Drawing on this research, we argue that executives' temporal orientations will serve as filters that shape which competitive stimuli executives selectively perceive and which stimuli they ignore, and as how they interpret the noticed stimuli, which in turn influences competitive behaviors. We examine the relationships between executives' temporal depth, competitive aggressiveness and firm performance.

\section{Executive temporal depth and competitive aggressiveness}

Research in psychology has identified several facets of people's temporal orientation, defined as inherent, persistent, and relatively stable tendencies in evaluating and interpreting time (Bluedorn, 2002; Zimbardo and Boyd, 1999). Studies in this stream have made significant progress in identifying and validating specific forms of temporal orientations such as time perspective (Zimbardo and Boyd, 1999) and temporal depth (Bluedorn, 2002). These temporal orientations hold considerable promise for sharpening the temporal lens and advancing theory and research on the subjective view of time in strategy (Ancona et al., 2001). Recently, Nadkarni and Chen (2014) found that CEO temporal focus (the degree to which CEOs characteristically devote attention to the past, present and future time frames) influenced rate of new product introductions. 
We examine a unique form of temporal orientation not addressed in previous researchtemporal depth, which refers to the temporal distance (or time horizons) into the past and the future that executives typically consider when contemplating events that have happened or may happen (Bluedorn, 2002; Bluedorn and Martin, 2008). Temporal depth is especially relevant to the context of strategy because time horizons are fundamental aspects of a firm's strategic orientation (Das, 1987) and influence a broad range of strategic behaviors such as technological and capital investments (Laverty, 1996; Marginson and McAulay, 2008; Souder and Bromiley, 2012). Katila and Chen (2008) found that the time horizon of search (early versus late) determined the frequency and innovativeness of new products introduced by the firm. Das (1987) found that executives in the same industry differed in their subjective time horizons, and these differences influenced the time horizons they considered in strategic planning. However, much of this research has examined mostly future time horizons. Gavetti and Levinthal (2000) argued that both backward and forward looking searches are essential to strategic adaptation. Temporal depth provides a comprehensive framework for understanding how time horizons considered in strategic decisions can stem from executives' innate orientation towards temporal distance into the past as well as the future.

Temporal depth subsumes two distinct dimensions, past temporal depth (PTD) and future temporal depth (FTD), each of which is associated with different information processing filters (Bluedorn, 2002). PTD, which captures how far back executives tend to go when considering past events (Bluedorn and Martin, 2008), has both pros and cons for decision-making. On the positive side, a long past temporal depth promotes a deeper understanding of the past and increases the chances of matching current situations with relevant lessons from prior situations to solve current problems quickly (Bluedorn, 2002; Clark and Collins, 1993). With the passage of time, events and situations become more understandable and explicable in terms of normative, situational, and objective forces (Taylor and Fiske, 1978). Whereas "people may have trouble seeing the forest for the trees' for near-past events and situations, the passage of time allows one to take a cognitive step back and view the larger canvas" (Miller and Porter, 1980: 537-538). Strategy researchers have also argued that cumulative past experience built through repeated observations and actions provides a 
deeper understanding of the technological and market context and reduces errors and false starts in initiating actions such as new product introductions (Helfat, 1997; Katila, 2002). At the same time, a long PTD can filter out critical aspects of the current context and prompt executives to consider distant past cues that may no longer be relevant. Such consideration of outdated information can inject errors and backtracking into evaluations of strategic alternatives (Brown and Eisenhardt, 1997). Nerkar (2003) advocated the virtues of "recency" in avoiding errors and competence traps that can hamper creation of new knowledge.

FTD--how far ahead executives tend to look when considering the future-is also considered a double-edged sword in decision making (Bluedorn, 2002). A long FTD promotes "pattern recognition," the ability to visualize long-term future changes that are not easily visible in the short run (Strathman et al., 1994). Such pattern visualization increases executives' awareness of distant future developments and allows them to make a priori investments to prepare for such developments. Executives with a short FTD may fail to foresee and prepare for potential future environmental opportunities and threats in advance (Bluedorn, 2002; Bluedorn and Martin, 2008). Strategy scholars also contend that the tendency to look into the long run can enhance competitiveness of firms in the marketplace by promoting foresight of management and by allowing managers to meticulously prepare for future developments (Miller, 2002). Overlooking the distant future can result in temporal myopia and short-termism, which prompt investment in technological and market opportunities that yield quick returns in the short run but can damage future competitive advantages of the firm (Chen and Miller, 2012, forthcoming; Laverty, 1996; Levinthal and March, 1993; Marginson and MacCaulay, 2008). However, a long FTD can make executives overcommitted to long-term goals and undermine their ability to adjust to critical short-term changes. Such hesitance to deviate from the long-term vision can create rigidities that can blind managers to changes in the short-term environmental conditions and create inertia in adapting to these changes (Levinthal and March, 1993).

We argue that executive temporal depth will create temporal filters that influence executives' awareness of the temporal significance of the competitive landscape and their consideration of 
competitive alternatives, in turn shaping competitive behaviors of firms. Specifically, we focus on the influence of executive temporal depth on a firm's competitive aggressiveness, which has emerged as a fundamental concept capturing inter-firm rivalry. Competitive aggressiveness reflects the degree to which a firm engages intensely with its rivals through its competitive repertoires, which are a set of market actions (e.g., price changes, product line or service alterations) used by a firm in a given year to proactively get ahead of rivals and to respond to rivals' actions (Yu et al., 2009). These action repertoires lie at the core of competitive aggressiveness and lend a holistic understanding of the approaches that competing firms stake in vying against one another (Chen et al., 2010a). A firm is said to have a high degree of competitive aggressiveness "if it has rapidly taken a large number of actions. The integrated consideration of both action volume and speed is essential for revealing the nuance of temporary advantage" (Chen et al., 2010a: 1413). Aggressiveness allows firms to proactively seize new opportunities ahead of rivals and to shorten the duration of advantages enjoyed by rivals. By undertaking more actions (volume) and acting more quickly in the wake of rivals' moves (speed), firms can proactively address the timedependent nature of competitive advantage (Andrevski, Brass and Ferrier, forthcoming; Eisenhardt, 1989; Ferrier, 2001). Therefore, time-sensitive elements of competitive behaviors lie at the heart of competitive aggressiveness. As Chen et al. (2010a: 1413) advocate, competitive aggressiveness "represents a fine-grained investigation at the micro firm-behavior level."

The relationships of PTD and FTD with competitive aggressiveness are likely tenuous because of the opposing mechanisms associated with them. PTD may promote aggressiveness by providing a deeper awareness of the broad historical competitive trends but may also hinder it by prompting executives to consider distant past cues that may no longer be relevant and by hampering their awareness of the nuances of the current competitive context. Similarly, FTD may enhance competitive aggressiveness by inducing executives to detect long-term competitive patterns and prepare for distant future developments ahead of competitors but may also inhibit aggressiveness by undermining executives' awareness of short-term changes. A potential resolution to the question of whether PTD and FTD enhance or inhibit competitive aggressiveness is examination of the 
environmental conditions within which executives operate, a point to which we now turn.

\section{The role of industry velocity}

"One of the hallmarks of strategy research is that relationships are typically contingent (i.e., it depends)"(Carpenter, 2002: 276). The contingency perspective in strategy has long recognized that the influence of executives' orientations on strategic behaviors is contingent on the demands posed by the environment such that a match between executive orientations and the environment results in superior firm performance (Keck, 1997; Lawrence and Lorsch, 1967). Consistent with the contingency perspective, the entrainment theory explains how the temporal adjustment of internal organizational activities to the temporal features of the environment results in superior adaptation and performance (Ancona and Chong, 1996). Entrainment is defined as the process by which activity cycles of one system synchronize to those of another, more dominant system (Ancona and Chong, 1996; Bluedorn, 2002). The dominant system, typically referred to as the time-giver, sets the tempo (i.e., the speed at which the activity is to be performed) of activity cycles to which the organization must entrain. The time-giver for an organization is its external environment, and effective adjustment to external temporal parameters is central to maximizing firm performance (Ancona and Chong, 1996). Successful environmental adaptation requires adjustment of temporal milestones, pacing, and sequencing of internal organizational activities to environmentally imposed time limits (Gersick, 1994; Sastry, 1997).

In this sense, executives are closely tied to environmental pacers such as technology, market, and competitor cycles, and temporal orientations of executives are likely to affect their ability to entrain to external temporal cycles (Ancona et al., 2001; Okhuysen and Waller, 2002). When executives' temporal orientations are compatible with the external temporal demands of the environment, executives can accurately detect and monitor external temporal contingencies and undertake responsive actions to adjust the internal activities of the firm to the external temporal requirements. In contrast, an inconsistency between the two can prompt executives to miscalculate environmental temporal demands and to undertake actions that are misaligned with these demands (Huy, 2001). Empirical studies have found that a fit between external environmental tempo setters 
such as hypercompetition (Chen et al., 2010a), dynamism (Nadkarni and Chen, 2014) and turbulence (Hambrick Geletkanycz, and Fredrickson, 1993) and managerial orientations maximized competitive behaviors and outcomes.

Drawing on the contingency and entrainment perspectives, we theorize a moderating effect of industry velocity (also referred to as industry clockspeed), which reflects the speed or rate at which new opportunities emerge and disappear (Davis et al., 2009; Eisenhardt and Martin, 2000). In the competitive context, opportunities embody new sources of gaining competitive advantages (e.g., technological and product innovations) and of destroying the advantages of rivals. In high-velocity industries, characterized by high rates of new product introductions, technological changes and competitive actions, competitive advantages are rapidly created and destroyed. High level of competitive activity in the form of new products, mergers and acquisitions, market expansion, and strategic alliances compress the temporal window of opportunities and push rivals into accelerating the pace of responses (Derfus et al., 2008). As Chen et al. (2010a: 1410) state, "firms engage in an escalating series of competitive actions simply to maintain pace with opponents." Conversely, in low-velocity industries, characterized by few and rare changes in products, technologies, and other competitive actions, incumbents enjoy longer temporal windows of opportunities and sustainable advantages from existing competitive actions (Nadkarni and Narayanan, 2007). Because industry velocity serves as a critical temporal contingency for incumbent firms, we propose that it will moderate the influence of executive temporal depth on competitive aggressiveness as well as the influence of competitive aggressiveness on firm performance.

We propose two broad sets of relationships. First, we expect that executive PTD and FTD will exhibit different patterns of relationships with competitive aggressiveness in high and low-velocity industries (H1 and $\mathrm{H} 2)$. Second, we argue that the positive effect of competitive aggressiveness on firm performance will be stronger in high-velocity industries than in low-velocity industries (H3).

\section{HYPOTHESES}

\section{Executive PTD and competitive aggressiveness}

PTD allows for depth of understanding of the historical context and increases the chances of quickly 
finding relevant lessons from a wide range of past actions and outcomes in undertaking present behaviors (Bluedorn, 2002; Miller and Porter, 1980; Zimbardo and Boyd, 1999). We propose that these attributes associated with executive PTD will promote awareness of the competitive landscape and in turn increase competitive aggressiveness in low-velocity industries, but inhibit competitive awareness and in turn aggressiveness in high-velocity industries. In low-velocity industries, where rate of technological and market changes is slow and rivals engage each other in similar ways over time, incumbents enjoy competitive advantages over a long period of time (Katila et al., 2012; Katila and Chen, 2008; Thomas and D'Aveni, 2009). Competitive interactions patterns in low-velocity environments emerge in the long run rather than the short run (D'Aveni et al., 2010; Eisenhardt and Martin, 2000). Because a long executive PTD is associated with "an increased ability to detect patterns by making it possible to perceive patterns displaying longer wavelengths" (Bluedorn and Martin, 2008: 15), detection of broad historical patterns that are not easily visible in the short run, may increase executives' awareness of hidden threats of rivals' actions and alert them to the necessity and urgency of initiating competitive actions. Such acute awareness of subtle opportunities and threats enhances executives' realization of the need for proactively undertaking a large number of new actions and responding in a speedy manner (Chen, 1996; Ferrier, 2001; Chen et al., 2007). By considering a longer time horizon, executives can draw on and combine many more pieces of information to quickly find many solutions to current competitive problems.

Conversely, in high-velocity industries, short product and process life cycles and new ways of problem solving quickly decreases the usefulness of past knowledge, experiences, and advantages (D’Aveni, 1994; Davis et al., 2009; Eisenhardt and Martin, 2000). Because competitive interaction patterns in high-velocity industries emerge in the short term rather than the long term (D’Aveni et al., 2010), “The past must not be interpreted as a simple recipe for success that can be used for a long time" (Bluedorn, 2002: 128). Rather, looking into the distant past may constrain executives' awareness of the short-term changes in the competitive landscape and prompt them to miscalculate the temporal window of opportunities in initiating actions and responses (Barringer and Bluedorn, 1999; Bluedorn and Martin, 2008). As a result, executives may face considerable 
delays in action-taking and may be left with only a small number of viable competitive action alternatives. By ignoring the current happenings and selectively perceiving distant historical events that may no longer be relevant, executives with a long PTD are likely to "become increasingly removed from other forms of experiences and more vulnerable to change in their environments... knowledge about and use of old competencies can inhibit efforts to change" (Levinthal and March, 1993: 102). Such lack of awareness can foster passivity and hamper quick precipitation of a large volume of competitive actions in these contexts (Bettis and Hitt, 1995; Marcel et al., 2011; Miller and Chen, 1994). Tripsas and Gavetti (2000) found that cumulative past experiences frequently constrained executives' timely competitive responses in the fast changing digital photography industry.

Hypothesis 1(H1): Industry velocity will moderate the relationship between executive PTD and competitive aggressiveness such that this relationship will be positive in low-velocity industries, but negative in high-velocity industries.

\section{Executive FTD and competitive aggressiveness}

In low-velocity industries, changes in technologies, competition and customer preferences are gradual and subtle, occur over relatively long cycles and are not easily visible in the short term (Chen et al., 2010a; Davis et al., 2009; Eisenhardt and Martin, 2000). We expect that a long FTD will positively influence firms' competitive aggressiveness in these environments, for two reasons. First, the competitive dynamics literature has argued that acute awareness of the competitive structure allows executives to notice and proactively respond to more opportunities and threats ahead of rivals (Chen et al., 2007; Ferrier, 2001). In slow-changing industries, where changes in the competitive environment occur gradually and only manifest in the long run (Eisenhardt and Martin, 2000; Nadkarni and Narayanan, 2007), the "pattern detection" ability associated with FTD is likely to promote an acute awareness of the competitive environment (Bluedorn and Martin, 2008). A long FTD may alert executives to potential developments in the distant future that are not easily visible in the short run, allowing them to quickly recognize and respond to more opportunities and threats ahead of rivals in a proactive manner, in turn resulting in greater competitive aggressiveness. Katila and Chen (2008) found that firms that initiated competitive moves over a longer time horizon 
engaged in an early search for new opportunities ahead of rivals and precipitated greater number of new products.

Second, strategy research has argued that in low velocity environments where changes are slow and can be gauged accurately in advance, an extensive and exhaustive a priori long-term strategic analysis can reduce potential barriers to identifying new opportunities as well as to coordinating and allocating resources needed to quickly realize multiple opportunities (Forbes, 2007). In contrast, a short executive FTD may hinder awareness of the long-term trajectories of technological, market and competitive changes. Because changes in the short term are few in lowvelocity industries (Davis et al., 2009), a short-term orientation may engender "temporal myopia" such that executives fail to proactively predict, prepare for, and act on long-term changes in the competitive environment (Chen and Miller, forthcoming; Levinthal and March, 1993: 110). Thus, a long executive FTD will facilitate competitive aggressiveness in low-velocity industries, whereas a short FTD will hinder aggressiveness.

In contrast, competitive dynamics scholars increasingly highlight the short time frame of competitive advantage in high-velocity industries, where technologies, markets, and competitors shift continually and competitive advantages erode very quickly (Bettis and Hitt, 1995; Chen et al., 2010a). In such industries, the advantages of FTD are likely to occur only up to certain levels, beyond which a longer FTD can hinder competitive aggressiveness, for several reasons (Barringer and Bluedorn, 1999; Bluedorn and Martin, 2008). First, an excessively long FTD “engenders a reluctance to deviate from a long-term view of the future despite short-term environmental change." (Barringer and Bluedorn, 1999: 425). Because changes occur frequently and in the short term rather than the long term, an overly long FTD may hinder awareness of critical short-term competitive changes (Barringer and Bluedorn, 1999), reducing both the speed and volume of viable competitive actions. Competitive dynamics research has stressed that flexibility in resource allocation and coordination is central to instilling competitive aggressiveness (Chen and Miller, 1995; Ndofor, Sirmon and He, 2011).

Second, unlike low-velocity industries, in which changes occur mainly in the long term, 
high-velocity industries are characterized by continuous and rapid changes in technological and competitive trajectories. Long-term predictions are difficult, and little concrete, detailed information about distant future events can be deduced in advance (Eisenhardt and Martin, 2000). As Bettis and Hitt (1995: 12) argued, "forecasting can be useful, but only in certain ways...the time frame of forecasting has shrunk, but it is still important." Because long-term trends are unknowable in such environments, a series of nested short- and medium-term decisions lends more flexibility than longterm oriented options (McGrath and Tschan, 2004). Thus, an excessive executive FTD may hinder awareness of the competitive context.

Together, this research suggests that in high-velocity industries, a very short FTD may give rise to temporal myopia, whereas a very long FTD may create rigidities. A moderate temporal depth may allow executives to develop tentative and multiple possible futures over a manageable time horizon, while continuously refining these futures based on concrete short-term feedback. Such balancing of not-too-distant future scenarios with short-term considerations allows executives to create an "up-to-date view of the future" without creating rigidities or biases associated with forecasting too far into the future (Brown and Eisenhardt, 1997: 29).

Hypothesis 2 (H2): Industry velocity will moderate the relationship between executive FTD and competitive aggressiveness such that this relationship will be linear positive in lowvelocity industries but inverted-U in high-velocity industries.

\section{Competitive aggressiveness and firm performance}

Aggressive firms can secure first mover advantages by proactively exploiting more opportunities ahead of competitors, can offset the efficacy of rivals' actions by introducing a large number of new actions and can defend their market positions through timely responses to rivals' actions (Chen et al., 2010a; D’Aveni, 1994; Ferrier et al., 1999). Action speed and volume are associated with improved firm profitability (Chen et al., 2010a; Hambrick et al., 1996) and market share (Ferrier et al., 1999; Hambrick et al., 1996).

Recent studies have argued that this effect may be stronger in fast-changing environments than in slow-changing environments (Chen et al., 2010a). The Austrian school emphasizes that firms undertake competitive actions to exploit the opportunity for profit (Kirzner, 1997) and it is 
critical that firms' actions are aligned with the window of opportunities embedded in specific markets. In fast-changing environments, where competitive advantage is temporary and actions become obsolete very quickly, competitive aggressiveness is even more critical to survival and success than in slow-changing environments, where competitive advantage may be relatively more sustainable and the ramifications of not acting quickly and intensely are less devastating. Chen et al. (2010a) found that aggressiveness was more positively related to firm performance in fast-changing environments than in slow-changing environments. Together, these arguments suggest that:

Hypothesis 3 (H3): Industry velocity will moderate the relationship between competitive aggressiveness and firm performance such that this relationship will be more positive in high-velocity industries than in low-velocity industries.

\section{METHODS}

\section{Time frame and sample}

The time frame for our study spanned the years 1995 to 2000 - executive temporal depth data from 1995 to 1999, competitive aggressiveness data from 1996 to 2000, and year-end firm performance data from 1996 to 2000. The economic conditions from 1995 to 2000 were relatively neutral, with no exogenous shocks such as the "soft landing" in 1995, September 11 in 2001 and financial crises from 2007 to 2008, all of which could disrupt the underlying competitive structures of industries in the short term and could confound predictions of incumbent firms' competitive behaviors (Marcel et al., 2011; Rindova et al.,, 2010; Yu et al., 2009).

The population for our study consisted of large (total assets $>\$ 1$ billion) (John, Lang, and Netter, 1992), established (at least 10 years old), and single business (> 70 percent revenue from primary business) U.S.-based firms available in the COMPUSTAT database between 1995 and 2000. Such principal single-business firms have interacted with and survived in their respective competitive environments over time and have a coherent competitive agenda (Derfus et al., 2008). We excluded firms belonging to industries (based on two-digit SIC code) where competition was not clearly observable through publicly available records (e.g., business service industries such as advertising agencies) or where measuring competitive actions such as new product introductions was difficult (e.g., the finance and insurance industries). We stratified the population of firms 
satisfying these criteria along industry lines and then randomly selected a representative sample of firms from each industry (e.g., Leiponen and Helfat, 2010). The final sample comprised 258 firms from 23 industries $(15-29$ percent firms in each industry).

\section{Data source for executive temporal depth}

We used three archival sources to derive executive temporal depth-letter to shareholders (LTS) in the annual reports (Nadkarni and Barr, 2008), management's discussion and analysis (MD\&A) in the 10-K forms and executive conference calls with analysts (Kimbrough and Louis, 2011). Such triangulation provides a comprehensive information set for construction of executive orientations and overcomes the biases associated with each archival source (Chatterjee and Hambrick, 2007). First, because these documents are published periodically, they are not laden with incomplete memory and retrospective biases and are more suitable for longitudinal designs (Nadkarni and Barr, 2008). Second, the consistent format of these documents based on prescriptions by the security and exchange commission (SEC) improves comparability across firms (Miller et al., 1996). Finally, these documents are non-intrusive and avoid problems of priming and researcher bias associated with eliciting orientations through interviews (Chatterjee and Hambrick, 2007).

LTS is an especially useful source for deriving temporal depth of executives because it is CEOs' public addresses of major priorities and themes that are important to the firm, including past achievements, current and future challenges, and plans for the future (Osborne, Stubbart, and Ramaprasad, 2001). Although LTS are signed and publicly attributed to the CEO, the strategic themes included in LTS represent "the socially negotiated perspectives of the CEO and other influential executives" (Marcel et al., 2011: 124). As the chief cognizer and chief attention regulator of the firm, the CEO must heed competing perspectives of other influential executives and integrate these perspectives for decision making. Therefore, LTS reflect the aggregate perceptions of executives who play a central role in shaping firm strategies (Marcel et al., 2011). LTS have been used to measure executives' perceptions of their environment (Nadkarni and Barr, 2008), their entrepreneurial focus (Cho and Hambrick, 2006), and their temporal focus (Nadkarni and Chen, 2014; Yadav, Prabhu and Chandy, 2007). 
The second source--MD\&A in 10-K forms--is useful in deriving temporal depth because "it is intended to give constituents the opportunity to look at the company through the eyes of management by providing both a short and long-term analysis of the business of the company" (Bryan, 1997: 286). It is required by law and is monitored by the SEC. Studies have shown that executives' assertions in MD\&A are consistent, have strong inter-coder reliability and shape future investments made by the firm (Bryan, 1997; Miller et al., 1996).

Finally, conference calls, where executives comment on past results and highlight the implications of current strategies for future financial performance, are becoming an increasingly important voluntary disclosure mechanism for firms. They are suitable for constructing executive temporal depth because they provide a greater volume of disclosure and emphasize both backwardlooking and forward-looking details (Kimbrough and Louis, 2011).

We obtained LTS from Mergent Online and MD\&A from Edgar database on www.sec.gov. Because conference call transcripts are open to the public only after 1999, we were able to get full transcripts of conference call for 1999 from the Lexis-Nexis academic database. However, we obtained selective executive assertions in the conference calls from 1995 to 1998 quoted in multiple published articles. We combined texts from the three sources into a single document separately for each year to construct yearly measures of executive PTD and FTD for each firm.

\section{Measures and controls}

Executive temporal depth. We used a three-step content analysis procedure to measure executive PTD and FTD. In step one, two coders blind to the study hypotheses independently identified statements in the two documents that specified exact numerical past and future time horizons ${ }^{1}$ : year (e.g., 1990, 2001, 2005) and time spans (e.g., six months, two years, decade) (PTD: $\kappa=0.84$, FTD:

\footnotetext{
${ }^{1}$ For firm-year observations (8.47 percent) with no explicit date or time frame, we followed prior literature and computed PTD and FTD from qualitative references of time frame in the executive documents (e.g., Stephan, Liberman, and Trope, 2011). Short-term (e.g., now, immediately, quick, shortly, and short-term), medium term (e.g., in the medium-term, in the coming years) and long-term (long time from now, long-term) references were assigned the average short-term, medium-term and long-term temporal distance in the executive documents of the focal firm for the remaining years in our dataset. Moreover, we also confirmed that dropping these qualitatively derived cases did not alter the results.
} 
$\kappa=0.80)$. Following is an example of a clear past time-span in Boeing's MD\&A in 1995:

"The major focus of development activities over the past three years has been the 777 widebody twinjet which entered service in May 1995."

The following quote illustrates an explicit future date in Merck's 1998 LTS:

“...Today, our medicines span 19 therapeutic categories...by 2002, it may be 24."

In step two, we ranked the sentences in ascending order based on the length of the time horizon (in years) from the shortest to the longest. In the final step, we computed PTD and FTD based on these rank-ordered sentences. Studies using an archival approach to assessing executives' orientations typically employ established scales to develop corresponding archival measures (Chatterjee and Hambrick, 2007). Accordingly, we used Bluedorn's (2002) six-item temporal depth index (TDI) (PTD: 3 items; FTD: 3 items; $\alpha: 0.88$ ) as a basis to compute three measures each of PTD and FTD from the rank-ordered sentences of time horizons. The three PTD items in TDI measure the time horizons that executives typically consider when thinking about the short-term past, medium-term past and long-term past on a 15-choice scale ranging from one day to 25 years. The three FTD items in TDI measure the same three time frames and use the same scale.

Consistent with TDI, we computed six measures of PTD and FTD. The first measure of PTD was the longest past date or time span cited in the three documents. Consistent with the long-term past item in TDI (Bluedorn, 2002), this measure indicates how far back executives look in discussing long-term historical issues. The second measure was the median past date or time span cited in the documents. This measure is consistent with the medium past item in TDI (Bluedorn and Martin, 2008). The final measure was the shortest past date or time span cited in the documents, which corresponds to the short-term past item in TDI (Bluedorn and Martin, 2008). The longest, median, and shortest future date or time span cited in the documents corresponded with the three FTD items in TDI. Cronbach's alpha was 0.71 for PTD and 0.78 for FTD. Therefore, we created composite measures of executive PTD and FTD by averaging the three individual items. Appendix I illustrates how our archival measures of PTD and FTD correspond with the items in TDI.

We validated the archival measures of PTD and FTD in a separate study of 176 middle 
managers $(70$ percent males, mean age $=35$ years, mean work experience $=10$ years $)$ enrolled in four sections of an MBA-level strategic management course at a major Eastern university. Archival measures of PTD $(\alpha=0.82)$ and FTD $(\alpha=0.79)$ were based on managers' submission of a threepage required case analysis write-up assignment of a Harvard business case. The executives also completed the TDI scale $(\alpha:$ PTD $=0.88, F T D=0.85)($ Bluedorn, 2002). As expected, archival PTD items correlated much more strongly to corresponding PTD items $(r=0.74-0.80)$ in TDI than to FTD items in TDI ( $\mathrm{r}=0.35$ to 0.42$)$, and archival FTD items had stronger correlations to the respective FTD items $(r=0.71-0.78)$ in TDI than to PTD $(r=0.32$ to 0.38$)$ in TDI. These results confirm the convergent and discriminant validity as well as reliability of our archival measures.

Competitive aggressiveness. Following previous studies in competitive dynamics, we used structured content analyses of news headlines to identify competitive actions of firms (Chen and Miller, 1994; Ferrier, 2001; Rindova et al., 2010; Yu et al., 2009). All news headlines were manually coded through a series of steps. First, the coders identified all news headlines for our sampled firms between 1996 and 2000 appearing in the Lexis/Nexis online database, which covers over 10,000 publications and has been used to identify competitive actions (Rindova et al., 2010). Second, two coders evaluated each headline to eliminate duplicate news releases of the same action and to determine whether a headline represented a competitive action, defined as "externallydirected specific and observable competitive moves initiated by a firm to enhance its competitive position." (Ferrier et al., 1999: 378). A total of 20,418 competitive actions were identified by the coders $(\kappa=0.81)$.

Following Chen et al. (2010), we created a composite competitive aggressiveness measure based on action volume and action speed. Action volume was total number of competitive actions initiated by a firm in a given year (Andrevski et al., forthcoming). Action speed was the average length of time lag in the focal firm's actions and rivals' immediately preceding actions in a given year (Derfus et al., 2008). The shorter the time lag, the faster the action speed. We reverse coded the speed measure by taking its inverse (Derfus et al., 2008). Factor analysis yielded a single factor (Eigen value: 1.74 ; factor loadings: action volume $=0.93$ and action speed $=0.93$ ). Therefore, we 
calculated a composite measure of competitive aggressiveness by averaging the standardized scores of speed and volume. Results based on the two individual dependent variables were consistent with those based on the composite measure. We lagged the yearly competitive aggressiveness measure behind the executive temporal depth by one year to ensure that executive temporal depth existed prior to the initiation of competitive actions, rather than ex post (Marcel et al., 2011).

Industry velocity. Industry velocity reflects how quickly opportunities appear and disappear in an industry (Davis et al., 2009; Eisenhardt and Martin, 2000). In a competitive context, creation and erosion of advantages are tied to how quickly competing firms undertake competitive actions in an industry (D’Aveni et al., 2010; Derfus et al., 2008). Firms controlling the most market share (> 80 percent) dominate the competitive structure of an industry and define the rules of competition for their industry (Derfus et al., 2008), thus setting the velocity for their industry. Using the procedures we explained earlier, we first identified competitive actions initiated by dominant firms in an industry and then computed industry velocity by averaging the competitive actions (total competitive actions/ number of firms) of these dominant firms in a given year. Examples of highvelocity industries are the computer (e.g., Dell), semiconductor (e.g., AMD), telecommunications (e.g., ADC) and motion picture and entertainment industries (e.g., AMC). Examples of low-velocity industries are metal and plastics (e.g., Ball Corp), office furniture (e.g., Steel Case), tire and rubber (e.g., Goodyear) and food packaging (e.g., Crown Holding).

Firm performance. Following prior competitive dynamics studies (e.g., Derfus et al., 2008), we used two accounting measures of performance--return on sales (ROS) and return on assets (ROA) - at the end of the same year as the competitive aggressiveness measure. Consistent with prior studies, we combined the z-scores of the two measures into a composite measure of firm performance (Bromiley and Harris, 2014). Results based on performance data at the end of the year following the competitive aggressiveness measure were consistent with the main results.

Control variables. We used several industry, firm and TMT controls in our analyses. Industry concentration (market share controlled by largest firms in an industry) creates entry barriers and restricts the intensity of competition in an industry (Ferrier, 2001). In highly 
concentrated industries, dominant firms are less pressured to engage in aggressive actions. In less concentrated industries, with few entry barriers, incumbents have to be aggressive to fend off attacks and retaliations from varied competitors. We used a Herfindahl index for industry concentration for each two-digit SIC code for each year (Derfus et al., 2008; Ferrier, 2001).

Industry unpredictability is a key contingency for incumbent firms (Bergh and Lawless, 1998). In unpredictable industries, where competitive cues are difficult to understand, firms quickly try out larger numbers of actions in the hope that at least a few can generate competitive advantages. In predictable industries, the competitive recipes are well known and firms can realize advantages with a few strategies. We regressed industry values of shipment over 5 years against time (19952000) and used the standard error of the regression coefficient related to a time dummy variable divided by the average value of industry's shipments to compute a standardized index of industry unpredictability (Bergh and Lawless, 1998).

High industry growth (percentage change in firm sales from the previous year to a focal year) (Derfus et al., 2008) provides competitive buffers for incumbents to expand sales and maintain their market share. However, firms in saturated industries are forced to search continually for new ways of competing simply to maintain their market share (Ferrier, 2001).

Finally, we controlled for industry homogeneity, which captures the degree to which incumbents in an industry follow well-defined recipes or patterns of strategic resource allocations (Zhang and Rajagopalan, 2003). In homogeneous industries, in which the causal relationship between strategy and performance is very clear, firms take fewer strategies to obtain a satisfactory level of performance. Conversely, in heterogeneous industries, where there is little clarity in competitive cues, incumbents quickly undertake many actions so that at least some will succeed. We used Zhang and Rajagopalan's (2003) computation of industry homogeneity based on six strategic dimensions (advertising intensity, R\&D intensity, plant and equipment newness, nonproduction overhead, inventory levels and financial leverage). For each dimension, we calculated variance among all the firms in each industry, standardized it for each dimension by the sample and multiplied it by -1 . We averaged the six standardized dimensions to derive an overall 
measure of industry homogeneity.

Smaller firms tend to be flexible, search for new opportunities and challenge the status quo (Smith et al., 2001), whereas large firms tend to be bureaucratic and resist competitive pressure (Ferrier et al., 1999). We measured firm size by the logarithm of the six-year average of total employees (Chen and Miller, 1994). We controlled for slack resources, which provide firms leeway to experiment with new actions and manage responses to rivals (Ferrier, 2001). We used three measures of slack: current ratio computed as current assets/current liabilities (available slack), debtequity ratio (potential slack), and the general and administrative expenses to sales ratio (recoverable slack) (Cheng and Kesner, 1997). Past performance increases reinforce the value of existing competitive actions, whereas performance decreases promote initiation of new actions (Chen and Miller, 1994). We measured the one-year rate of change in ROA and ROS (McDonald, Khanna, and Westphal, 2008) immediately preceding competitive aggressiveness data.

Because greater TMT demographic diversity and size foster diversity of opinions and perspectives, broader specialization of skills increase and greater awareness of various alternatives, they initiate a large number of complex competitive actions (Ferrier, 2001; Hambrick et al., 1996; Wiersema and Bantel, 1992). We defined TMT members as those individuals at the two highest levels of management identified in the Dunn and Bradstreet reference book of corporate management. TMT heterogeneity was computed by three measures - educational background (Blau index; business, science, liberal arts, law, engineering and others), functional background (Blau index; engineering/ R\&D, finance/accounting, legal, human resources management, manufacturing, logistics, purchasing, public relations, and general management) and organizational tenure (coefficient of variation: SD/mean) (Ferrier, 2001; Hambrick et al., 1996). TMT composite heterogeneity index was the sum of the three standardized individual heterogeneity measures.

\section{ANALYSES AND RESULTS}

\section{Analyses}

Model testing. We used the generalized least squares (GLS) models, which correct for and provide consistent estimates in the presence of groupwise heteroskedasticity, cross group correlation, and 
within-group auto-correlation (Greene, 2003) in pooled cross-sectional observations such as ours (258 firms for five years: 1186 firm-years). The Hausman test (Hausman, 1978) results were insignificant. So, we used random effects (rather than fixed effects) estimation procedures.

We used the established stepwise moderation approach (Aiken and West, 1991) to test for the interaction effects of executive temporal depth and industry velocity on competitive aggressiveness. We entered the controls in model 1 and added the main effects of executive temporal depth and industry velocity in model 2 and the hypothesized interaction effects between executive temporal depth and industry velocity in model 3 . We further tested the main effects of executive temporal depth separately for high- and low-velocity industries. Such a median splitsample approach is recommended for testing non-linear interactions and to better understand bidirectional moderation (e.g., Morse, Nanda, and Seru, 2011). We used identical procedures to test for the moderating effects of industry velocity on the relationship between competitive aggressiveness and firm performance.

We mean centered predictor variables in all the regression models to minimize multicollinearity (Aiken and West, 1991). The variance inflation factors for all independent variables were below the recommended level of 10 .

Correction for endogeneity. A host of unmodeled factors could influence executive temporal depth, competitive aggressiveness and firm performance. To correct for this endogeneity, we followed the procedures recommended by Chatterjee and Hambrick (2007) and Hambrick (2007). Accordingly, we regressed executive PTD and FTD on industry dummies (based on twodigit SIC codes) and firm (past performance, slack resources, and R \& D expenditures) variables one year prior to executive PTD and FTD variables. Using regression coefficients for these industry and firm variables, we calculated each executives' predicted PTD and FTD score and included these values as endogeneity correction control variables in testing the moderation models.

\section{Results}

Table 1 provides descriptive statistics and correlations among the study variables. Table 2 and Table 3 summarize results from the regression analyses. 
'Please insert Tables 1, 2 and 3 around here'

In Table 2, the interaction term executive PTD $\times$ industry velocity is significant $(B=-0.08$, S.E. $=0.03, p<0.05)$. In the split-sample tests, PTD is positively related to competitive aggressiveness in low-velocity industries $(\mathrm{B}=0.06, \mathrm{~S} . \mathrm{E} .=0.02, p<0.05)$ but negatively related to aggressiveness in high-velocity industries $(\mathrm{B}=-0.16, \mathrm{~S} . \mathrm{E} .=0.05, p<0.01)$. These results support H1.

The value of distant past is evident in this quote from executives of PPG industry (the top 25 percent in competitive aggressiveness) in the low-velocity chemical manufacturing industry:

"The first coat, which provides rust protection, was the result of a chemistry that PPG patented 20 years ago and today is the industry standard."-LTS, 1997.

Executives of Texas Industries, ranked in the bottom 25 percent in competitive aggressiveness in the low-velocity construction materials industry, cited short-term past orientation:

"We make our own opportunities for profitable growth - and that's exactly what happened last year."-LTS, 1998

The assertions of executives in high-velocity industries were the opposite. This quote of Liz Claiborne executives (top 25 percent in competitive aggressiveness) explains how focusing on "today" rather than the distant past is key in the high-velocity cosmetic industry.

“...our environment is in constant flux, and effectively managing change requires different skills than in the past. Today, we prize the ability not just to sell, but to analyze and understand, not just to design and create, but to do so within the context of current customer and Consumer preferences..." - LTS, 2000.

However, executives of Dionex (bottom 25 percent in competitive aggressiveness) in the high-velocity Analytical Laboratory Instrument Manufacturing industry, cited the distant past:

"We continue to improve our products, strengthen our customer relationships and expand the applications for our systems. This has been our strategy for the past twenty years and will continue to guide our future growth."-LTS, 1998

The interaction term, FTD square $\times$ industry velocity $(\mathrm{B}=-0.09, \mathrm{~S} . \mathrm{E} .=0.04, p<0.01)$, is significant. In the split-sample tests, FTD is positively related to competitive aggressiveness in lowvelocity industries $(\mathrm{B}=0.07, \mathrm{~S} . \mathrm{E} .=0.02, p<0.01)$. In high-velocity industries, the positive FTD 
term $(\mathrm{B}=0.15, \mathrm{~S} . \mathrm{E} .=0.07, p<0.05)$ and the negative FTD-square term $(\mathrm{B}=-0.11, \mathrm{~S} . \mathrm{E} .=0.04, p<$ 0.01 ) support the inverted- $\mathrm{U}$ shaped relationship in $\mathrm{H} 2$.

This quote from Alberto-culver executives (top 25 percent in aggressiveness) imply the importance of a long-term future horizon in the low-velocity household consumer industry:

"We continue to aggressively prune underperforming brands and stock keeping units from our portfolio in order to concentrate on products that have the greatest long-term potential for the company... We have been able to achieve strong top and bottom line growth while continuing to make substantially increased marketing investments that will benefit our business in the long run."- LTS, 1997

Conversely, executives of Tredegar, a firm low in competitive aggressiveness (bottom 25

percent) in the low-velocity plastic films industry, exhibited a short-term future orientation.

"Looking ahead, Tredegar's immediate challenge is to accelerate growth... Building value in today's world depends on our ability to use information and knowledge to drive innovation"-LTS, 1997, 1998

However, assertions of executives in high-velocity industries were the opposite. Executives of Western Digital (top 25 percent in competitive aggressiveness) explained the value of intermediate FTD in adapting to market changes in the high-velocity computer hard disk industry:

“... With the vast and rapidly growing market before us, our challenge is to execute properly the plans we've developed to serve it. Western Digital continues to have adequate capital resources for the near-and intermediate-term... "- LTS, 1999.

Executives from Biomet inc., a medical device manufacturing company low on competitive aggressiveness (bottom 25 percent) depicted a long-term future orientation:

"As we look forward to our next twenty years of growth, Biomet is committed to expanding its global market share by improving upon the high quality products and services offered to customers and patients throughout the world"-LTS, 1997

In Table 3, competitive aggressiveness relates positively to firm performance $(B=0.14$, S.E. $=0.03, p<0.001)$ for the full sample as well as for the low- $(\mathrm{B}=0.14$, S.E. $=0.06, p<0.05)$ and high-velocity groups $(\mathrm{B}=0.11, \mathrm{~S} . \mathrm{E} .=0.03, p<0.01)$. Industry velocity $\times$ competitive aggressiveness has a positive effect on firm performance $(\mathrm{B}=0.05, \mathrm{~S} . \mathrm{E} .=0.03, p<0.1)$. Thus, $\mathrm{H} 3$ is marginally supported.

\section{DISCUSSION}




\section{Theoretical implications}

We built on and extended research on time in competitive dynamics by examining how executive temporal orientation interacts with industry velocity in shaping competitive aggressiveness. This study yielded two broad sets of results. First, it illustrates that the role of executive temporal depth in shaping competitive aggressiveness is contingent on industry velocity. Executive PTD promoted aggressiveness in low-velocity industries but hindered it in high-velocity industries, whereas FTD promoted aggressiveness in low-velocity industries but had an inverted-U relationship in highvelocity industries. Second, PTD and FTD showed different relationship patterns to aggressiveness in the two contexts. In low-velocity contexts, both PTD and FTD enhanced aggressiveness. However, in high-velocity contexts, PTD hampered aggressiveness, but FTD enhanced it up to a point, beyond which it was dysfunctional. These results specify the environmental boundary conditions of executive temporal orientation in shaping competitive aggressiveness and highlight the importance of considering temporal direction (past versus future) in addition to time horizons. These results have two key implications for research on competitive dynamics.

First, competitive dynamics research has explained how industry-level temporal forces such as hypercompetition (D’Aveni et al., 2010), velocity (Eisenhardt and Martin, 2000), dynamism (Davis et al., 2009), uncertainty (Chen and Miller, 1994) and nascent versus established industries (Chen et al., 2010b) serve as time givers and determine the temporariness or sustainability of advantages enjoyed by incumbents from their competitive actions. Firms that successfully match the temporal aspects of their micro competitive actions to the temporal features of the environment enjoy superior performance, whereas firms that fail to adapt to their environment face major losses (Ancona et al., 2001; Davis et al., 2009; Katila et al., 2012). Our results add to this body of research by suggesting a third temporal force-executives' temporal orientation. Our results demonstrate that innate temporal orientations of executives are central to promoting competitive adaptation through speedy precipitation of a large volume of competitive actions. Thus, this study highlights the importance of subjective perspective of time in understanding competitive phenomena.

At the same time, the effects of executive temporal orientation are contingent on macro 
temporal forces - industry velocity. Our results suggest that executive PTD and FTD orientations that promote competitive aggressiveness and in turn superior performance in high-velocity environments but may be dysfunctional in low-velocity environments and vice versa. An important implication of these moderation results is that not only is executive temporal orientation an important force in shaping temporally rooted competitive behaviors, but also that executive temporal orientation cannot be considered in isolation of macro temporal features of the environment. Rather, temporal features of the macro industrial environments serve as boundary conditions for the relationship between executive temporal orientation and firm behaviors. This result is especially notable because research on objectively-based macro temporal forces and subjective perspective of time has progressed along independent lines. Our results suggest that the two perspectives are complementary and together provide a more complete understanding of how time manifests in competitive behaviors. The integration of macro, micro and subjective temporal forces presented in this study is consistent with the entrainment theory, which suggests that the degree of "temporal fit" between managers' executive temporal orientations and external clocks set by the environmental factors promotes effective adaptation, whereas a misfit between the two hinders adaptation (Ancona and Chong, 1996; Ancona et al., 2001).

The results of this study constitute a first step in explicating the interaction between subjective temporal forces and macro (environmental) factors in predicting competitive behaviors and firm performance. Future studies could further explore the mechanisms through which executive temporal orientation promotes or hinders competitive behaviors in high- and low-velocity environments. Several streams of research are pertinent in theorizing these mediating mechanisms this regard. Literature on temporal aspects of strategic decision-making is particularly relevant in this regard. Because executive temporal orientations represent innate and relatively stable temporal tendencies (Bluedorn, 2002; Zimbardo and Boyd, 1999), they are likely to shape temporal heuristics, pacing and sequencing rules described in the strategic decision making literature (Bingham and Eisenhardt, 2011; Gersick, 1994; Sastry, 1997). Because different environments necessitate different temporal rules and heuristics, the relationship of executive PTD and FTD to aggressive 
behaviors may be mediated by these unique context-relevant rules and heuristics. For example, a short temporal depth is associated with spontaneity and flexibility, whereas a long temporal depth promotes systematic preparation for the future (Bluedorn, 2002; Zimbardo and Boyd, 1999). Short PTD and medium FTD may dispose executives to develop loose and flexible temporal ordering and sequencing rules in undertaking firm strategies, all of which are suitable in dynamic environments. In contrast, long PTD and FTD may prompt executives to develop in advance a complete, clearly ordered map of all future choice points that are pertinent to undertaking aggressive behaviors in stable environments.

Another potential mediation mechanism is the notion of perceived competitive tension (Chen et al., 2007). For example, in high velocity industries, executives with low PTD and medium FTD may experience higher competitive tension and are more aggressive in response to what they believe will happen in future, not what happened in the past. As such, PTD and FTD could trigger different forms of perceived competitive tension: reflective competitive tension derived by what happened in the past vs anticipatory competitive tension derived by beliefs of what might happen in the future. These reflective vs anticipatory competitive tension will enhance or hamper competitive aggressiveness.

Future studies could combine insights on executives temporal depth from this study with strategic decision making literature and perceived competitive tension literature to pose this question: How do executive temporal orientations influence competitive behaviors differently in different environments? Thus, the temporal mechanisms specified in the strategic decision making literature and different forms of perceived competitive tension could serve as potential mediators in environment-specific relationships between executive temporal orientation and firm actions.

Second, prior research has considered only future time horizons (Das, 1987; Laverty, 1996; Marginson and MacCaulay, 2008; Souder and Bromiley, 2012). We demonstrated the role of both past and future time horizons in shaping competitive behaviors. Interestingly, the distinction between past and future time horizons seems pertinent to understanding competitive behaviors in high-velocity environments but not in low-velocity environments. Substantively, the relationships 
of executive PTD and FTD were consistent in low-velocity industries, but PTD and FTD exhibited different patterns of relationships in high-velocity industries. Whereas a short PTD yielded superior competitive aggressiveness and firm performance, a moderate FTD maximized competitive aggressiveness and firm performance in high-velocity industries. These results are consistent with the temporal depth literature, which argues that the information processing mechanisms associated with PTD (deeper understanding and learning) are distinct from those associated with FTD (visionary thinking and pattern detection) (Bluedorn, 2002). Bluedorn and Martin (2008) found that PTD and FTD of entrepreneurs related differently to perceived temporal flexibility, work stress and preference for working fast. Our results suggest that the differences between PTD and FTD are pronounced in some environments (high velocity) but not in others (low velocity).

\section{Limitations and conclusions}

Our study is bound by some limitations. Our findings based on single business firms may not apply to diversified firms facing multi-market competition. Similarly, the five-year time frame of our study captured a unique time period for the nature of competitive interactions among firms and this time period corresponding to our results limits generalizability of our findings.

In conclusion, this study underscores the substantive value of executive temporal orientation in understanding competitive behaviors and firm performance in different industry contexts. We hope that the promising results of this study stimulate further research on executive temporal orientation, firm behaviors and outcomes. Such research could improve our understanding of how time manifests in competitive behaviors and firm strategies. 


\section{REFERENCES}

Aiken L, West S. 1991. Multiple regression: Testing and interpreting interactions. Newbury Park, CA: Sage.

Ancona DG, Chong CL.1996. Entrainment: Pace, cycle, and rhythm in organization behavior. Research in Organizational Behavior, 18: 251-285.

Ancona, DG, Okhuysen GA. Perlow LA. 2001. Taking time to integrate temporal research. Academy of Management Review 26(4): 512-529.

Andrevski G, Brass DJ, Ferrier WJ. Forthcoming. Alliance portfolio configurations and competitive action frequency. Journal of Management.

Barringer BR, Bluedorn AC. 1999. The relationship between corporate entrepreneurship and strategic management. Strategic Management Journal 20(5): 421 - 444.

Bergh DD, Lawless MW. 1998. Portfolio restructuring and limits to hierarchical governance: The effects of environmental uncertainty and diversification strategy. Organization Science 9(1): 87-102.

Bettis RA, Hitt MA. 1995. The new competitive landscape. Strategic Management Journal 16(S1): 7-19.

Bingham CB, Eisenhardt KM. 2011. Rational heuristics: the 'simple rules' that strategists learn from process experience. Strategic Management Journal 32(13): 1437-1464.

Bluedorn AC. 2002. The human organization of time: Temporal realities and experience. Stanford University Press: Stanford, CA.

Bluedorn AC, Martin G. 2008. The time frames of entrepreneurs. Journal of Business Venturing 23(1): 1-20.

Bromiley, P., and J. D. Harris. 2014. A comparison of alternative measures of organizational aspirations. Strategic Management Journal 35 (3): 338-357.

Brown SL, Eisenhardt KM. 1997. The Art of Continuous Change: Linking Complexity Theory and Timepaced Evolution in Relentlessly Shifting Organizations. Administrative Science Quarterly 42(1): 134.

Bryan SH. 1997. Incremental information content of required disclosures contained in management discussion and analysis. Accounting Review 72(2): 285-301.

Carpenter MA. 2002. The implications of strategy and social context for the relationship between top management team heterogeneity and firm performance. Strategic Management Journal 23(3): 275284.

Chatterjee A, Hambrick DC. 2007. It's all about me: Narcissistic chief executive officers and their effects on company strategy and performance. Administrative Science Quarterly 52(3): 351-386.

Chen M-J, Lin H-C, Michel JG. 2010a. Navigating in a hypercompetitive environment: the roles of action aggressiveness and TMT integration. Strategic Management Journal 31(13): 1410-1430.

Chen EL, Katila R, McDonald R, Eisenhardt KM. 2010b. Life in the fast lane: Origins of competitive interaction in new vs. established markets. Strategic Management Journal 31(13): 1527-1547.

Chen MJ. 1996. Competitor analysis and interfirm rivalry: Toward a theoretical integration. Academy of Management Review 21(1): 100-134.

Chen M-J., Miller D. 1994. Competitive attack, retaliation and performance: An expectancy-valence framework. Strategic Management Journal 15(2): 85-102.

Chen M-J, Miller, D. 2012. Competitive dynamics: Themes, trends, and a prospective research platform. Academy of Management Annals. 
Chen MJ, Miller D. Forthcoming. Reconceptualizing competitive dynamics: A multidimensional framework. Strategic Management Journal.

Chen M-J, Su K-H, Tsai W. 2007. Competitive tension: The awareness-motivation-capability perspective. Academy of Management Journal, 50(1): 101-118.

Cheng JL, Kesner IF. 1997. Organizational slack and response to environmental shifts: The impact of resource allocation patterns. Journal of Management 23(1): 1-19.

Cho TS, Hambrick DC. 2006. Attention as the mediator between top management team characteristics and strategic change: The case of airline deregulation. Organization Science 17(4): 453-469.

Clark LF, Collins JE. 1993. Remembering old flames - How the past affects assessments of the present. Personality and Social Psychology Bulletin 19(4): 399-408.

D’Aveni RA. 1994. Hypercompetition: Managing the Dynamics of Strategic Maneuvering. Free Press: New York.

D'Aveni RA, Dagnino GB, Smith KG. 2010. The age of temporary advantage. Strategic management journal 31(13): 1371-1385.

Das TK. 1987. Strategic planning and individual temporal orientation. Strategic Management Journal 8(2): 203-209.

Das TK. 2004. Strategy and time: Really recognizing the future. In H. Tsoukas, J. Shepherd (Eds.), Managing the Future: Foresight in the Knowledge Economy: 58-74. Oxford, UK: Blackwell.

Davis JP, Eisenhardt KM, B.Bingham C. 2009. Optimal structure, market dynamism, and the strategy of simple rules. Administrative Science Quarterly 54(3): 413-452.

Derfus PJ, Maggitti PG, Grimm CM, Smith KG. 2008. The red queen effect: Competitive actions and firm performance. Academy of Management Journal 51(1): 61-80.

Eisenhardt KM, Martin JA. 2000. Dynamic capabilities: what are they? Strategic Management Journal 21(10/11): 1105-1122.

Ferrier WJ. 2001. Navigating the competitive landscape: The drivers and consequences of competitive aggressiveness. Academy of Management Journal 44(4): 858-877.

Ferrier WJ, Smith KG, Grimm CM. 1999. The role of competitive action in market share erosion and industry dethronement: A study of industry leaders and challengers. Academy of Management Journal 42(4): 372-388.

Forbes D. 2007. Reconsidering the strategic implications of decision comprehensiveness. Academy of Management Review 32(2): 361-376.

Gavetti G, Levinthal D. 2000. Looking Forward and Looking Backward: Cognitive and Experiential Search. Administrative Science Quarterly 45(1): 113-137.

Gersick CJG. 1994. Pacing strategic change: the case of a new venture. Academy of Management Journal 37(1): 9-45.

Greene WH. 2003. Econometric Analysis: Pearson-Prentice Hall.

Hambrick DC. 2007. Upper echelons theory: An update. Academy of Management Review 32(2): 334-343.

Hambrick DC, Cho TS, Chen M-J. 1996. The Influence of Top Management Team Heterogeneity on Firms' Competitive Moves. Administrative Science Quarterly 41(4): 659-684.

Hambrick DC, Geletkanycz MA, Fredrickson JW. 1993. Top executive commitment to the status-quo - Some tests of its determinants. Strategic Management Journal 14(6): 401-418. 
Hambrick DC, Mason PA. 1984. Upper echelons: The organization as a reflection of its top managers. Academy of Management Review 9(2): 193-206.

Hausman JA. 1978. Specification Tests in Econometrics. Econometrica, 46(6): 1251-1271.

Helfat CE. 1997. Know-how and asset complementarity and dynamic capability accumulation: The case of R\&D. Strategic Management Journal 18(5): 339-360.

Huy QN. 2001. Time, temporal capability, and planned change. Academy of Management Review 26(4): 601623.

John K, Lang LHP, Netter J. 1992. The voluntary restructuring of large firms in response to performance decline. The Journal of Finance, 47(3): 891-917.

Judge WQ, Miller A. 1991. Antecedents and outcomes of decision speed in different environmental contexts. Academy of Management Journal 34(2): 449-463.

Katila R. 2002. New product search over time: past ideas in their prime? Academy of Management Journal 45(5): 995-1010.

Katila R, Chen EL. 2008. Effects of search timing on innovation: the value of not being in sync with rivals. Administrative Science Quarterly 53(4): 593-625.

Katila R, Chen EL, Piezunka H. 2012. All the right moves: How entrepreneurial firms compete effectively. Strategic Entrepreneurship Journal 6(2): 116-132.

Keck SL. 1997. Top management team structure: Differential effects by environmental context. Organization Science 8(2): 143-156.

Kimbrough MD, Louis H. 2011. Voluntary disclosure to influence investor reactions to merger announcements: an examination of conference calls. The Accounting Review 86(2): 637-667.

Kirzner IM.1997. Entrepreneurial discovery and the competitive market process: an Austrian approach. Journal of Economic Literature 35(1): 60-85.

Laverty KJ. 1996. Economic "Short-Termism": The Debate, the unresolved issues, and the implications for management practice and research. Academy of Management Review 21(3): 825-860.

Lawrence PR, Lorsch JW. 1967. Differentiation and integration in complex organizations. Administrative science quarterly: 1-47.

Lee C-H, Venkatraman N, Tanriverdi H, Iyer B. 2010. Complementarity-based hypercompetition in the software industry: Theory and empirical test, 1990-2002. Strategic Management Journal, 31(13): $1431-1456$.

Levinthal DA, March JG. 1993. The myopia of learning. Strategic Management Journal 14(S2): 95-112.

Leiponen A, Helfat CE. 2010. Innovation objectives, knowledge sources, and the benefits of breadth. Strategic Management Journal 31(2): 224-236.

Livengood RS, Reger RK. 2010. That's our turf! Identity domains and competitive dynamics. Academy of Management Review 35(1): 48-66.

Marcel JJ, Barr PS, Duhaime IM. 2011. The influence of executive cognition on competitive dynamics. Strategic Management Journal 32(2): 115-138.

Marginson D, McAulay L. 2008. Exploring the debate on short-termism: a theoretical and empirical analysis. Strategic Management Journal 29(3): 273-292.

McDonald ML, Khanna P, Westphal JD. 2008. Getting them to think outside the circle: Corporate governance, CEOs' external advice networks, and firm performance. Academy of Management Journal 51(3): 453 - 475 
McGrath JE, Tschan F. 2004. Temporal matters in social psychology: Examining the role of time in the lives of groups and individuals. American Psychological Association.

Miller KD. 2002. Knowledge inventories and managerial myopia. Strategic Management Journal 23(8): 689706.

Miller D, Chen M-J. 1994. Sources and consequences of competitive inertia: A study of the U.S. airline industry. Administrative Science Quarterly 39(1): 1-23.

Miller DT, Porter CA. 1980. The effects of temporal perspective on the attribution process. Journal of Personality and Social Psychology, 39: 532-541.

Morse A, Nanda V, Seru A. 2011. Are incentive contracts rigged by powerful CEOs? Journal of Finance 66(5): 1779-1821.

Nadkarni S, Barr PS. 2008. Environmental context, managerial cognition, and strategic action: an integrated view. Strategic Management Journal 29(13): 1395-1427.

Nadkarni S, Chen J. 2014. Bridging yesterday, today, and tomorrow: CEO temporal focus, environmental dynamism, and rate of new product introduction. Academy of Management Journal 57 (6): 18101833.

Nadkarni S, Narayanan VK. 2007. Strategic schemas, strategic flexibility, and firm performance: The moderating role of industry clockspeed. Strategic Management Journal 28(3): 243-270.

Ndofor HA, Sirmon DG, He XM. 2011. Firm resources, competitive actions and performance: Investigating a mediated model with evidence from the in-Vitro diagnostics industry. Strategic Management Journal 32(6): 640-657.

Nerkar A. 2003. Old is Gold? The value of Temporal exploration in the creation of New knowledge. Management Science 49(2): 211-229.

Okhuysen GA, Waller MJ. 2002. Focusing on midpoint transitions: An analysis of boundary conditions. Academy of Management Journal 45(5): 1056-1065.

Osborne JD, Stubbart CI, Ramaprasad A. 2001. Strategic groups and competitive enactment: A study of dynamic relationships between mental models and performance. Strategic Management Journal 22(5): 435-454.

Porac JF, Thomas H, Baden-Fuller C. 1989. Competitive groups as cognitive communities: The case of Scottish knitwear manufacturers. Journal of Management studies 26(4): 397-416.

Porac JF, Thomas H. 1990. Taxonomic mental models in competitor definition. Academy of Management Review 15(2): 224-240.

Reger RK, Huff AS. 1993. Strategic groups: A cognitive perspective. Strategic Management Journal 14(2): 103-123.

Rindova V, Ferrier WJ, Wiltbank R. 2010. Value from gestalt: how sequences of competitive actions create advantage for firms in nascent markets. Strategic Management Journal 31(13): 1474-1497.

Sastry MA. 1997. Organizational Change. Administrative Science Quarterly 42(2): 237-275.

Smith KG, Ferrier WJ, Ndofor H (eds.). 2001. Competitive Dynamics Research: Critique and future directions M. Hitt, R.E. Freeman, \& J. Harrison (eds.), London: Blackwell Publishers.

Souder D, Bromiley P. 2012. Explaining temporal orientation: Evidence from the durability of firms' capital investments. Strategic Management Journal 33(5): 560-579.

Stephan E, Liberman N, Trope Y. 2011. The effects of time perspective and level of construal on social distance. Journal of Experimental Social Psychology 47(2): 397-402. 
Strathman A, Gleicher F, Boninger DS, Edwards CS. 1994. The consideration of future consequences Weighing immediate and distant outcomes of behavior. Journal of Personality and Social Psychology 66(4): 742-752.

Taylor SE, Fiske ST.1978. Salience, attention, and attribution: top of the head phenomena. In B. Leonard (Ed.), Advances in Experimental Social Psychology11: 249-288: Academic Press.

Tripsas M, Gavetti G. 2000. Capabilities, cognition, and inertia: Evidence from digital imaging. Strategic Management Journal 21(10/11): 1147-1161.

Tsai W, Su K, Chen MJ. 2011. Seeing through the eyes of a rival: Competitor acumen based on rival-centric perceptions. Academy of Management Journal 54(4): 761-778.

Wiersema MF, Bantel KA. 1992. Top management team demography and corporate strategic change. Academy of Management Journal 35(1): 91-121.

Yadav MS, Prabhu JC, Chandy RK. 2007. Managing the future: CEO attention and innovation outcomes. Journal of Marketing 71(4): 84-101.

Yu T, Subramaniam M, Cannella Jor. AA. 2009. Rivalry deterrence in international markets: Contingencies governing the mutual forbearance hypothesis. Academy of Management Journal 52(1): 127-147.

Zhang Y, Rajagopalan N. 2003. Explaining new CEO origin: Firm versus industry antecedents. Academy of Management Journal 46(3): 327-338.

Zimbardo P, Boyd J. 1999. Putting time in perspective: A valid, reliable individual-differences metric. Journal of Personality and Social Psychology 77(6): 1271-1288. 
Table 1 Descriptive Statistics and Correlations ${ }^{\text {a }}$

\begin{tabular}{|c|c|c|c|c|c|c|c|c|c|c|c|c|c|c|c|}
\hline Variables & Mean & S.D. & 1 & 2 & 3 & 4 & 5 & 6 & 7 & 8 & 9 & 10 & 11 & 12 & 13 \\
\hline \multicolumn{16}{|l|}{ Controls } \\
\hline 1. Firm size $^{\mathrm{b}}$ & 3.19 & 0.74 & 1 & & & & & & & & & & & & \\
\hline 2. Organizational slack & 0.97 & 1.33 & -0.18 & 1 & & & & & & & & & & & \\
\hline 3. Past performance change & 0.02 & 0.20 & -0.00 & -0.05 & 1 & & & & & & & & & & \\
\hline 4. TMT size & 6.18 & 1.18 & 0.14 & -0.07 & -0.02 & 1 & & & & & & & & & \\
\hline 5. TMT heterogeneity & 0.01 & 0.70 & -0.02 & 0.02 & -0.03 & 0.29 & 1 & & & & & & & & \\
\hline 6. Industry concentration & 0.04 & 0.05 & 0.03 & 0.03 & -0.01 & 0.05 & 0.04 & 1 & & & & & & & \\
\hline 7. Industry unpredictability & 0.02 & 0.02 & -0.01 & 0.09 & 0.06 & 0.09 & 0.03 & 0.57 & 1 & & & & & & \\
\hline 8. Industry growth & 0.06 & 0.12 & 0.01 & 0.03 & 0.03 & -0.08 & -0.05 & 0.06 & 0.12 & 1 & & & & & \\
\hline 9. Industry homogeneity & 0.10 & 0.51 & 0.15 & -0.04 & -0.03 & -0.01 & -0.02 & 0.23 & 0.10 & 0.06 & 1 & & & & \\
\hline \multicolumn{16}{|l|}{ Study variables } \\
\hline 10. Industry velocity & 26.72 & 29.70 & -0.05 & -0.03 & -0.01 & 0.04 & 0.08 & -0.12 & -0.08 & -0.20 & -0.60 & 1 & & & \\
\hline 11. Executive PTD ${ }^{1}$ & 4.97 & 2.57 & -0.06 & 0.02 & 0.02 & -0.10 & -0.01 & 0.02 & 0.00 & -0.05 & -0.11 & 0.09 & 1 & & \\
\hline 12. Executive FTD ${ }^{2}$ & 4.88 & 3.01 & -0.04 & 0.00 & 0.04 & 0.01 & -0.01 & -0.05 & 0.00 & -0.00 & -0.03 & -0.04 & 0.18 & 1 & \\
\hline 13. Competitive aggressiveness & -0.05 & 0.55 & 0.26 & -0.00 & 0.07 & 0.10 & 0.07 & -0.03 & -0.00 & -0.00 & -0.20 & 0.15 & -0.01 & 0.02 & 1 \\
\hline 14. Performance & 0.00 & 0.94 & -0.07 & 0.07 & 0.25 & -0.00 & -0.10 & 0.06 & 0.06 & -0.03 & -0.12 & 0.07 & 0.06 & 0.05 & 0.15 \\
\hline
\end{tabular}

${ }^{a}$ Correlations with value greater than $|0.06|$ are significant at $p<0.05$

${ }^{\mathbf{b}}$ Logarithm transformation

${ }^{1}$ Executive PTD: Executive Past Temporal Depth

${ }^{2}$ Executive FTD: Executive Future Temporal Depth

$\mathrm{N}=1186$ 
Table 2. Moderated regression results for executive temporal depth, industry velocity and competitive aggressiveness

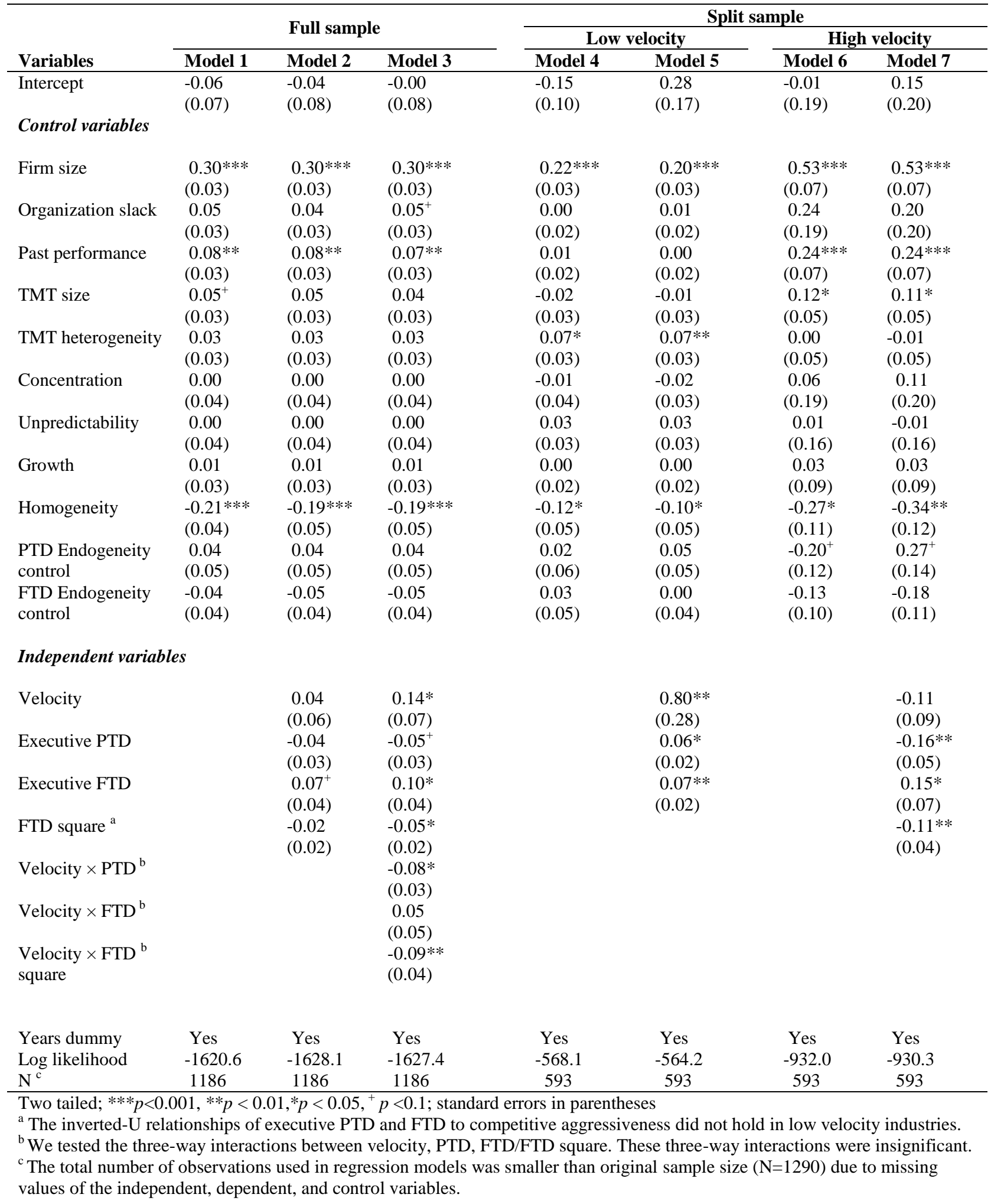


Table 3. Moderated regression results for competitive aggressiveness, industry velocity, and firm performance

\begin{tabular}{|c|c|c|c|c|c|c|c|}
\hline \multirow[t]{3}{*}{ Variables } & \multirow{2}{*}{\multicolumn{3}{|c|}{ Full sample }} & \multicolumn{4}{|c|}{ Split sample } \\
\hline & & & & \multicolumn{2}{|c|}{ Low velocity } & \multicolumn{2}{|c|}{ High velocity } \\
\hline & Model 1 & Model 2 & Model 3 & Model 4 & Model 5 & Model 6 & Model 7 \\
\hline Intercept & $\begin{array}{l}-0.02 \\
(0.09)\end{array}$ & $\begin{array}{l}-0.01 \\
(0.09)\end{array}$ & $\begin{array}{l}-0.03 \\
(0.09)\end{array}$ & $\begin{array}{l}-0.17 \\
(0.12)\end{array}$ & $\begin{array}{l}-0.28 \\
(0.26)\end{array}$ & $\begin{array}{c}0.14 \\
(0.15)\end{array}$ & $\begin{array}{c}0.14 \\
(0.15)\end{array}$ \\
\hline \multicolumn{8}{|l|}{ Controls } \\
\hline Firm size & $\begin{array}{l}-0.03 \\
(0.03)\end{array}$ & $\begin{array}{l}-0.07 * \\
(0.03)\end{array}$ & $\begin{array}{l}-0.06^{*} \\
(0.03)\end{array}$ & $\begin{array}{l}-0.04 \\
(0.04)\end{array}$ & $\begin{array}{l}-0.07 \\
(0.04)\end{array}$ & $\begin{array}{c}0.08^{+} \\
(0.05)\end{array}$ & $\begin{array}{l}0.03 \\
(0.05)\end{array}$ \\
\hline Slack resource & $\begin{array}{l}0.08^{* *} \\
(0.03)\end{array}$ & $\begin{array}{c}0.07 * \\
(0.03)\end{array}$ & $\begin{array}{l}0.07 * \\
(0.03)\end{array}$ & $\begin{array}{c}0.02 \\
(0.03)\end{array}$ & $\begin{array}{c}0.02 \\
(0.03)\end{array}$ & $\begin{array}{l}0.79 * * * \\
(0.11)\end{array}$ & $\begin{array}{l}0.74 * * * \\
(0.11)\end{array}$ \\
\hline Past performance & $\begin{array}{l}0.25 * * * \\
(0.03)\end{array}$ & $\begin{array}{l}0.24 * * * \\
(0.03)\end{array}$ & $\begin{array}{l}0.24 * * * \\
(0.03)\end{array}$ & $\begin{array}{l}0.24 * * * \\
(0.03)\end{array}$ & $\begin{array}{l}0.24 * * * \\
(0.03)\end{array}$ & $\begin{array}{l}0.23 * * * \\
(0.05)\end{array}$ & $\begin{array}{l}0.21 * * * \\
(0.05)\end{array}$ \\
\hline TMT size & $\begin{array}{c}0.04 \\
(0.03)\end{array}$ & $\begin{array}{l}0.03 \\
(0.03)\end{array}$ & $\begin{array}{l}0.03 \\
(0.03)\end{array}$ & $\begin{array}{c}0.01 \\
(0.04)\end{array}$ & $\begin{array}{l}0.01 \\
(0.04)\end{array}$ & $\begin{array}{l}0.09 * \\
(0.04)\end{array}$ & $\begin{array}{c}0.08^{+} \\
(0.04)\end{array}$ \\
\hline TMT heterogeneity & $\begin{array}{l}-0.13 * * * \\
(0.03)\end{array}$ & $\begin{array}{l}-0.14 * * * \\
(0.03)\end{array}$ & $\begin{array}{l}-0.13 * * * \\
(0.03)\end{array}$ & $\begin{array}{l}-0.05 \\
(0.04)\end{array}$ & $\begin{array}{l}-0.06 \\
(0.04)\end{array}$ & $\begin{array}{l}-0.19 * * * \\
(0.04)\end{array}$ & $\begin{array}{l}-0.19 * * * \\
(0.04)\end{array}$ \\
\hline Concentration & $\begin{array}{l}0.12 * * \\
(0.05)\end{array}$ & $\begin{array}{l}0.12^{* *} \\
(0.05)\end{array}$ & $\begin{array}{l}0.12 * * \\
(0.05)\end{array}$ & $\begin{array}{l}0.14 * * \\
(0.05)\end{array}$ & $\begin{array}{l}0.14^{* *} \\
(0.05)\end{array}$ & $\begin{array}{l}-0.21 \\
(0.14)\end{array}$ & $\begin{array}{l}-0.23 \\
(0.14)\end{array}$ \\
\hline Unpredictability & $\begin{array}{l}-0.01 \\
(0.04)\end{array}$ & $\begin{array}{l}-0.01 \\
(0.04)\end{array}$ & $\begin{array}{l}-0.01 \\
(0.04)\end{array}$ & $\begin{array}{l}-0.01 \\
(0.05)\end{array}$ & $\begin{array}{l}-0.01 \\
(0.05)\end{array}$ & $\begin{array}{l}-0.02 \\
(0.13)\end{array}$ & $\begin{array}{l}-0.02 \\
(0.13)\end{array}$ \\
\hline Growth & $\begin{array}{l}-0.04 \\
(0.03)\end{array}$ & $\begin{array}{c}-0.03 \\
(0.03)\end{array}$ & $\begin{array}{l}-0.03 \\
(0.03)\end{array}$ & $\begin{array}{l}-0.02 \\
(0.03)\end{array}$ & $\begin{array}{l}-0.01 \\
(0.03)\end{array}$ & $\begin{array}{l}-0.08 \\
(0.07)\end{array}$ & $\begin{array}{l}-0.08 \\
(0.07)\end{array}$ \\
\hline Homogeneity & $\begin{array}{l}-0.04 \\
(0.05)\end{array}$ & $\begin{array}{c}0.00 \\
(0.05)\end{array}$ & $\begin{array}{c}0.00 \\
(0.05)\end{array}$ & $\begin{array}{c}0.03 \\
(0.06)\end{array}$ & $\begin{array}{c}0.05 \\
(0.07)\end{array}$ & $\begin{array}{l}-0.05 \\
(0.09)\end{array}$ & $\begin{array}{l}-0.03 \\
(0.1)\end{array}$ \\
\hline \multicolumn{8}{|l|}{ Independent variables } \\
\hline Velocity & & $\begin{array}{c}0.03 \\
(0.06)\end{array}$ & $\begin{array}{c}0.03 \\
(0.06)\end{array}$ & & $\begin{array}{l}-0.22 \\
(0.41)\end{array}$ & & $\begin{array}{l}-0.01 \\
(0.07)\end{array}$ \\
\hline Competitive aggressiveness & & $\begin{array}{l}0.14 * * * \\
(0.03)\end{array}$ & $\begin{array}{l}0.11 * * * \\
(0.03)\end{array}$ & & $\begin{array}{c}0.14^{*} \\
(0.06)\end{array}$ & & $\begin{array}{l}0.11 * * \\
(0.03)\end{array}$ \\
\hline Velocity $\times$ aggressiveness & & & $\begin{array}{c}0.05^{+} \\
(0.03)\end{array}$ & & & & \\
\hline Year dummy & Yes & Yes & Yes & Yes & Yes & Yes & Yes \\
\hline Log likelihood & 1637.9 & 1631.6 & 1632.9 & 798.7 & 797.9 & 824.6 & 824.0 \\
\hline $\mathrm{N}^{\mathrm{a}}$ & 1186 & 1186 & 1186 & 593 & 593 & 593 & 593 \\
\hline
\end{tabular}




\section{Appendix I Derivation of archival measures of PTD and FTD based on temporal depth index}

\begin{tabular}{|c|c|c|}
\hline & TDI items $^{\text {a }}$ & Corresponding archival measure in our study \\
\hline \multirow[b]{2}{*}{ PTD } & $\begin{array}{l}\text { When I think about things that happened recently, I } \\
\text { usually think about things that happened this long ago }\end{array}$ & $\begin{array}{l}\text { The shortest time span between the past date cited in combined } \\
\text { text and the date of the combined text from LTS, MD\&A and } \\
\text { Conference call transcripts }\end{array}$ \\
\hline & $\begin{array}{l}\text { When I think about things that happened a middling } \\
\text { time ago, I usually think about things that happened this } \\
\text { long ago }\end{array}$ & $\begin{array}{l}\text { The median time span between the past date cited in combined } \\
\text { text and the date of the combined text from LTS, MD\&A and } \\
\text { Conference call transcripts }\end{array}$ \\
\hline \multirow[b]{2}{*}{ FTD } & $\begin{array}{l}\text { When I think about the short-term future, I usually think } \\
\text { about things this far ahead }\end{array}$ & $\begin{array}{l}\text { The shortest future time span between the future date cited in the } \\
\text { combined text and the date of the combined text from LTS, } \\
\text { MD\&A and Conference call transcripts }\end{array}$ \\
\hline & $\begin{array}{l}\text { When I think about the mid-term future, I usually think } \\
\text { about things this far ahead }\end{array}$ & $\begin{array}{l}\text { The median future time span between the future date cited in the } \\
\text { combined text and the date of the combined text from LTS, } \\
\text { MD\&A and Conference call transcripts }\end{array}$ \\
\hline
\end{tabular}

a: Each item has 15 options: One day, One week, Two weeks, One month, Three months, Six months, Nine months, One year, Three years, Five years, Ten years, Fifteen years, Twenty years, Twenty-five years 